\title{
Pressure Injury Prevention: Patient Education for Spinal cord Injury Patients- The I mportance of Teaching Nurses to Teach
}

\section{Thomas Sheppard}

${ }^{1}$ Eastern New Mexico University

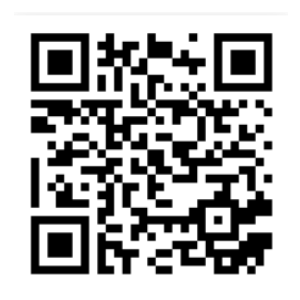

\begin{abstract}
Patient education is an essential component of preventing the occurrence of pressure injuries. Patients that have suffered a spinal cord injury are at severe risk of developing pressure injuries throughout their lifetimes. There are many factors that nurses need to be aware of to provide effective patient education and promote positive patient outcomes. While all nurses can provide basic information, many of them are not proficient teachers. To enhance patient education, this article review will identify various important factors that affect the ability of spinal cord injury patients to learn and the nurse's ability to provide effective patient education about risk factors for pressure injury development preventive measures to reduce the risk of developing pressure injuries.

Keywords: Pressure injury, pressure ulcer, spinal cord injury, patient education, nursing patient education, and possible combinations of these.

Copyright : (C) 2022 The Authors. Published by Medical Editor and Educational Research Publishers Ltd. This is an open access article under the CC BY-NC-ND license (https://creativecommons.org/licenses/by-nc-nd/4.0/).
\end{abstract}

\section{1 | INTRODUCTION}

P ressure Injuries

hire-threatening complication of spinal cord injury according to the Paralyzed Veterans of America (PVA, 2014) (1). The increased risk of pressure injuries for this patient population, throughout their lifetimes, is multi-factorial and necessitates additional patient education to reduce the risk factors and promote early identification of skin alterations to reduce further tissue damage. Pressure injuries occur in more than two and a half million people each year

Supplementary information The online version of this article (https://doi.org/10.52845/JMRHS/20225-2-5) contains supplementary material, which is available to authorized users.

Corresponding Author: Thomas Sheppard

Eastern New Mexico University 


\section{PRESSURE INJURY PREVENTION: PATIENT EDUCATION FOR SPINAL CORD INJURY PATIENTS- THE IMPORTANCE OF TEACHING NURSES TO TEACH \\ in the United States and significantly impact the lives of these patients, causing severe pain, infection, and \\ 3 | FACTORS AFFECTING PATIENT EDUCATION} possibly death (AHQR, 2014) (2).

Patient education is the responsibility of all nurses in all care settings. Communication and the transference of information about pressure injury prevention, including all aspects of risk, is an under researched area, despite frequently identified as a common factor in root-cause analysis of complaints related to pressure injury development and patient complaints about care (Fletcher, 2020) (3). . Spinal cord injury (SCI ) nurses are faced with providing evidence-based patient education to patients from diverse populations, with widely varying learning abilities, and multiple co-morbid conditions that impact their ability to learn. While most nurses are able to provide basic educational information to their patients, not all nurses are effective teachers. To enhance patient learning and the ability of nurses to provide needed education, nurses need to learn to be proficient and effective educators. This literature review will examine available literature to establish a common theme among SCI patients, pressure injury prevention, patient education, and nurses as educators.

This literature review will examine related journal articles, texts, and clinical practice guidelines dated 2004 through 2021. Databases utilized for this review include Google Scholar, Medline Plus, PubMed, and Science Direct.

\section{2 | PRESSURE INJURY PREVALENCE}

According to AHQR (2014), more than two and a half million people develop pressure injuries each year in the United States. Nearly all spinal cord injury patients will develop at least one pressure injury during their lifetime. They are among the highest risk population for developing pressure injuries with an incidence of $25-66 \%$ (Kruger et al., 2013) (4) . Pressure injuries are the second lead cause of hospitalization for this patient population (PVA, 2014). Pressure injury prevention is crucial for patients suffering spinal cord injuries and patient education is an essential component of preventing the development of these wounds.
To effectively educate persons with spinal cord injuries about pressure injury prevention one must consider factors that affect the individual's ability to learn. There is little research on the impact of patient education for management of patients with spinal cord injuries (SCI) at risk for pressure injury development (Robineau et al., 2019) (5). There are many areas of knowledge that can enable SCI patients to reduce their risks of developing pressure injuries. There are also many factors that can impede a patient's ability to learn including behavioral disorders, cognitive ability, emotional state, language barriers, previous knowledge and experiences, physical limitations, reading ability, as well as cultural beliefs and differences.

According to Durwin \& Reese-Weber (2018) (6) behavior disorders such as anxiety can impair the learner's ability to learn due to impaired ability to concentrate and reduced ability to recall information. They also point out that depression can reduce interest and participation in learning activities. ADHD and conduct disorder have also been identified as behaviors that impair learning ability. An individual's previous knowledge and experiences may also impact their ability or willingness to learn new information. Many SCI patients have successfully avoided pressure injuries for many years, but upon development of these wounds believe that the wound was the result of outside factors and that their historical avoidance methods are good enough, leading to them not wanting further education and denying possible contributing factors. Patients that have physical limitations may require adaptive equipment to facilitate learning such as audio books, video presentations, hearing aids, or other equipment to permit seeing or hearing new information. Motivational factors may be closely linked to the individual's locus of control, a belief that either external or internal factors are the cause of pressure injury development.

A patient's cognitive ability greatly affects their ability to learn new information. Many patients with SCI have also suffered traumatic brain injuries. This may affect their thinking processes, attention span, 
ability to focus on instructions, and may cause disruptive behaviors. Patients may also have other debilitating conditions such as dementia and Parkinson's disease. The nurse providing education to these individuals may need to adapt educational materials for these patients of direct their teaching to family members and caregivers.

\section{4 | PATIENT EDUCATION}

Patient education is the responsibility of nurses in all care settings. SCI nurses need to have a thorough understanding of pressure injury risks, prevention measures, skin assessment, wound assessment, AND TREATMENT and additionally need to be aware of physiological and biochemical changes that occur following a spinal cord injury. Nurses normally provide the patient with printed materials and a quick overview of these topics then should prompt the patient for feedback to determine comprehension and retention of the information that has been provided.

It is important for nurses to assess their patients' needs, concerns, readiness to learn, learning preferences, support, and barriers to learning prior to providing them with new information (Medline Plus, n.d.) (7) . It is recommended that health care providers assume that all patients and caregivers may have difficulty comprehending information provided during patient education and that educational material should be provided in ways that anyone can understand (Health Literacy / Healthy People 2020, n.d.) (8) . Most nurses have been taught to provide patient education material that is at an eighthgrade level. Every patient is a unique individual, and their learning abilities may vastly differ. This necessitates all patient education be individualized for the specific needs of the patient. The amount of information provided and the patient's ability to focus on learning may be limited and may require multiple short sessions to achieve learning.

\section{I TEACHING THE NURSE TO TEACH}

Not all nurses need to BE nurse educators, but in order to effectively teach their patients, nurses need to have a basic understanding of factors that impair an individual's ability to learn. Strategies that can be implemented to enhance the patients' ability to learn can also be beneficial. The volume of information that needs to be delivered can require nurses to delegate some of their responsibilities to support staff in order to have sufficient time TO focus on the patient and their educational needs.

Teaching is an art and a science that requires focused practice to achieve mastery (Ulrich, 2006) (9). ULRICH continues on to point out that although patient and family education is a major responsibility for nurses, they are rarely taught how to teach, that there are competencies to be mastered and theories to be learned before a nurse is ready to teach. The importance of understanding developmental and cognitive levels, learning abilities and disabilities, behavioral factors, cultural influences, language barriers, and other factors that may alter one's ability to learn is a consideration that most nurse have not been taught. They also have not been taught teaching strategies to address these issues. To enhance a nurse's ability to be an effective teacher they need to be taught how to teach, conditions that may impair one's learning ability, have a sound knowledge base of the information being taught, and have the time to spend with the patient to promote learning.

Many institutions offer training in 1 competence, patient centered communication, and some have developed mentorship programs to improve the ability of nurses to provide effective teach for their patients. A training course that was developed, focusing on teach-back strategies for patient education, focusing on adult learning theory, covered topics including learners' need to know, self-concepts, prior experience, orientation to learning, and motivation to learn (Fidyk et al., 2014) (10) . Although the participants in this study were motivated to change behaviors related to patient education, the limited size of the study group resulted in statistically insignificant data. As with other studies related to patient education, the researchers concluded that further investigation is needed. These topics, as discussed above, can provide the nurse with needed information to effectively teach patients. Whether teaching other nurses or patients training courses, preceptorships, 
and mentorships can benefit nurses in learning to teach.

\section{6 | CONCLUSION}

The importance of patient education for the prevention of pressure injuries among spinal cord injury patients is essential for these individuals for lead healthy, productive lives. There are many factors that impact learning among this population that nurses need to be aware of. It is also important for SCI nurses to have knowledge of teaching methods that may enhance the patient's learning ability and motivation to learn. Pressure injuries are a lifelong complication of SCI and can have detrimental effects on the lives of the patient and those close to them. By providing SCI nurses with evidence-based knowledge related to SCI, pressure injury risks, preventive strategies, assessment skills, educational limitations, and methods to enhance learning it may be possible to promote positive patient outcomes for this highrisk patient group.

Healthcare Institutions can greatly enhance patient education by offering training courses, mentorships, and preceptorships focused on teaching nurses to accurately assess their patients' learning needs, preferred methods of learning, factors that impair their ability to lean, and teaching strategies to meet the needs of individual patients. Nurse educators can play a significant role in precepting, mentoring, and teaching SCI nurses to be effective teachers for the SCI patient population.

\section{REFERENCES}

1. Paralyzed Veterans of America. (2014). Pressure injury prevention and treatment following a spinal cord injury: a clinical practice guideline for health-care professionals (2nd ed.). Retrieved November 29, 2021 ;Available from: https:/www.pva.org/CMSPages/ GetFile. aspx? guid=77e3be6a-bad2-43c7-9e491c9460a8785f.

2. Agency for Healthcare Research and Quality. (2014). Preventing pressure ulcers in hospitals.
Retrieved November 29, 2021 ;Available from: https://www.ahrq.gov/patient-safety/settings/ hospital/resource/pressureulcer/tool/index.html.

3. Fletcher J. Pressure ulcer education 8: Giving information to patients. Nursing Times [Online]; 116(5), 31-33. Retrieved November 30, 2021 . Nursing Times. 2020;Available from: https: //www.nursingtimes.net/clinical-archive/tissueviability/pressure-ulcer-education- 8 -givinginformation-to-patients-20-04-2020/.

4. Kruger EA, Pires M, Ngann Y, Sterling M, Rubayi S. Comprehensive management of pressure ulcers in spinal cord injury: Current concepts and future trends. The Journal of Spinal Cord Medicine,. 2013;36(6):572-585.

5. Robineau S, Nicholas B, Mathieu L, Durufle A, Leblong E, Frauder B, et al. Assessing the impact of a patient education programme on pressure ulcer prevention in patients with spinal cord injuries. Journal of Tissue Viability. 2019;28(4):167-172. doi:https://doi.org/10.101 6/j.jtv.2019.06.001.

6. Durwin CD, Reese-Weber M. EdPsych modules. 2018;

7. Medline Plus. (n. d.). Choosing effective patient education materials. Retrieved November 30, 2021,;Available from: https://medlineplus.gov/ ency/patientinstructions/000455.htm.

8. Health Literacy Healthy People 2020. (n.d.). HealthyPeople.gov. Retrieved November 30, 2021;Available from: https://www. healthypeople.gov/2020/topics-objectives/ topic/social-determinants-health/interventionsresources/health-literacy.

9. Ulrich B. Teaching nurses to teach: A good investment for all. Nephrology Nursing. 2006;

10. Fidyk L, Ventura K, Green K. Teaching nurses how to teach: Strategies to enhance the quality of patient education. , . Journal for Nurses in Professional Development. 2014;30(5):248253. doi:https://doi.org/10.1097/NND.0000000 000000074. 
How to cite this article: Sheppard T. Pressure Injury Prevention: Patient Education for Spinal cord Injury Patients- The I mportance of Teaching Nurses to Teach. Journal of Medical Research and Health Sciences. 2022;1791-1795. https://doi .org/10.52845/JMRHS/2022-5-2-5 